\title{
COULOMB STRESS CHANGES DUE TO RECENT ACEH EARTHQUAKES
}

\author{
Madlazim \\ Physics Department, Faculty Mathematics and Sciences of Surabaya State University \\ (UNESA) J1. Ketintang, Surabaya 60231, Indonesia. \\ e-mail: malazim@unesa.ac.id
}

\begin{abstract}
Coulomb stress change analysis has been applied to understand whether the 2013/07/02 ( $\left.M_{w}=6.1\right)$ has been triggered by 2013/01/21 earthquake $\left(M_{w}=6.1\right)$ the proximity to failure on the Aceh segment of Sumatra Fault Zone (SFZ). We examine the problem of how one earthquake might trigger another using Coulomb stress changes plotting. To plot the Coulomb stress changes, we used Global CMT data for the both earthquakes and used GEOFON data for manually revised epicenters of its aftershocks. The earthquakes are located on Aceh segment of the historic no recorded large earthquake. Coulomb stress changes modeling of the both earthquakes and plot their aftershocks. Surprisingly, the 2013/07/02 earthquake is located on increasing Coulomb stress changes region of 2013/01/21 earthquake plotting. Here explain that the 2013/07/02 earthquake has been triggered by the 2013/01/21 earthquake. Further, the two aftershocks of the 2013/07/02 earthquake is located on increasing Coulomb stress changes region of 2013/07/02 earthquake plotting. So that, the aftershocks has been triggered by increasing Coulomb stress changes of the 2013/07/02 earthquake.
\end{abstract}

Keywords: Coulomb stress changes, trigger and aftershocks 


\section{INTRODUCTION}

Significant progress of method that could be used in forecasting the locations of aftershocks and subsequent mainshocks by considering the theoretical stress changes induced by past earthquakes has been made by [1] in recent years. The method, known as Coulomb stress changes, assumes that an earthquake may be modelled as a slip dislocation within a uniform elastic half-space. By using analytic solutions for the displacement and stress in the surrounding medium and assuming that subsequent earthquakes result from frictional instability along faults.

Fault interactions and triggering caused by earthquake rupture have been studied in great detail in the past one decade [2] [3] [4]. These studies can broadly be classified into two categories [5]. The first category relates to the correlation between the larger events and the subsequent smaller events and examining the short time periods, while the second category relates to the fault interaction between larger events on larger timescales. Focus on these studies are the effect of earthquakes on seismic hazard and how their occurrence influences nearby events. Results of both categories have significant implications on the seismic hazard assessment in any region [6].

Increasing Coulomb stress places on the regions most likely to experience aftershocks in the days following a mainshock. The Coulomb stress changes analysis predicts an increased probability of aftershocks, occurring some distance from the mainshock hypocenter [7]. Coulomb stress changes analysis offers the possibility to calculate the time-evolution of stress within a fault system and to forecast the regions with heightened probability of mainshocks in the future. For example, a demonstration of this potential is the successful forecast of the 1999 Izmit, Turkey earthquake (Parsons et al. 2000) [8] and the analysis of Coulomb stress changes for $\mathrm{M}_{\mathrm{w}}>7$ earthquakes along the North Anatolian Fault during the 20th Century. Coulomb stress changes triggering of mainshocks is expected to give rise to time dependent recurrence statistics. The probability of occurrence of mainshocks of a given magnitude will depend upon the recent seismic history in the surrounding region [7].

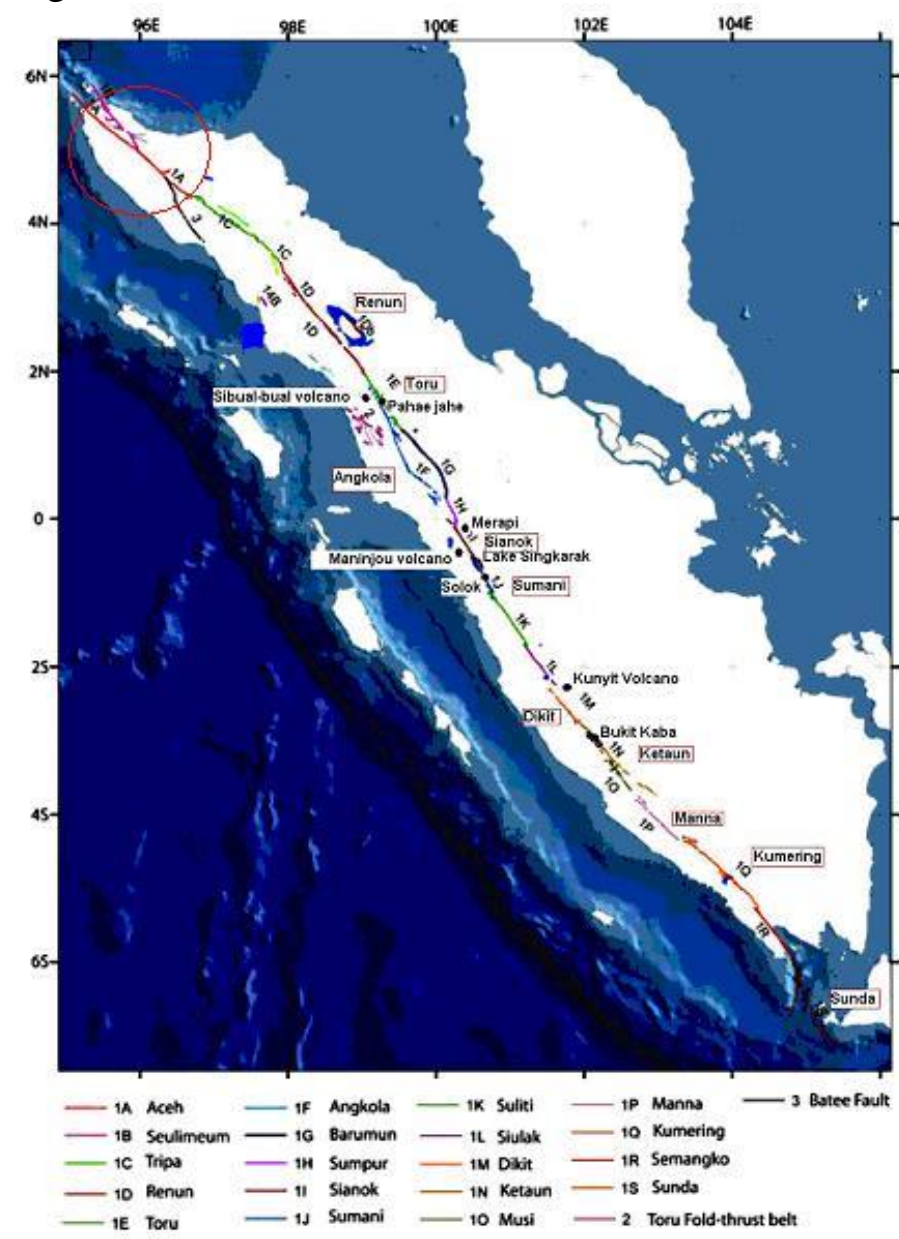

Figure 1. Modified map of the geometrically defined segments of the SFZ, based on [9] and [10] also showing the Aceh segment of interest in this research (red cilcle region).

The approaches to predict recurrence statistics, based upon the Gutenberg- Richter relation do not take account for this time-dependency of earthquake occurrence. There has been some debate as to whether stress interactions need be considered when estimating the seismic risk of the Sumatra 
island. This study constitutes a first step towards addressing this issue. This study analysed the recent strong earthquakes of this years that occurred in the Aceh segment of Sumatran Fault Zone (Figure $1)$, namely the $2013 / 01 / 21 \quad\left(M_{\mathrm{w}}=6.1\right)$ earthquake, 2013/07/02 $\left(\mathrm{M}_{\mathrm{w}} \quad=6.1\right)$ earthquakes and its two aftershocks. The valid source parameters of the both strong earthquakes can be known from Global CMT (www.globalcmt.org). In view of the worldwide studies suggesting good correlation between the zone of aftershocks and increased static stress changes, we test this hypothesis and investigate whether it can broadly constrain some of the source parameters of these earthquakes. We assume that the aftershocks of these earthquakes occurred due to a change in regional stress, which is caused by the coseismic static stress change due to the main earthquake. Thus spatial variation in the aftershocks helped in constraining some of the source parameters of the earthquakes.

\section{METHODOLOGY}

The method for analyzing the Coulomb stress changes due to an earthquake is well described by [1]. The appropriate starting point is to model the earthquake as a slip dislocation on a rectangular fault plane or planes representing the earthquake source zone. One may then compute the change in both shear and normal stress caused by the earthquake, using the [11] analytic Green's Function for stress changes due to rectangular dislocations in an uniform, elastic half-space. If one further assumes an orientation for faults in the region surrounding the earthquake, one may compute the net change in Coulomb stress along these surrounding faults. Coulomb stress changes $(\Delta S)$ is defined as the difference between the static shear stress changes $(\Delta \tau)$ and the effective normal stress changes $(\Delta \sigma)$ multiplied by an effective coefficient of friction $(\mu)$, namely:
$\Delta \mathrm{S}=\Delta \tau-\mu^{\prime} \Delta \sigma[12]$

The static shear stress changes (assumed positive in the direction of fault slip) and effective normal stress changes (positive if compressive) on the fault plane caused by the main shock respectively, while $\mu^{\prime}$ is defined as $\mu^{\prime}=\mu(1-B)$, where $B$ is the Skempton's coefficient whose value lies between 0 and 1 . The stress changes in an elastic half-space due to slip on a rectangular fault are computed using Coulomb 3.3. For all the earthquakes discussed here a shear modulus of $3.2 \times 10^{5}$ bar and a Poisson ratio [1] of 0.25 are assumed. We assume here that the effective coefficient of friction of all faults is approximately 0.4 . Coulomb stress calculations are relatively insensitive to the choice of effective friction coefficient so this value is considered reasonable [1]. Failure is encouraged if $\Delta \mathrm{S}$ is positive, and discouraged if it is negative. Thus it is considered that the aftershocks generally occur in the zone of increased $\Delta S$.

An increase in Coulomb stress changes on a fault may thus be interpreted as a loading of the fault towards brittle failure (i.e. earthquake rupture). Conversely, a decrease in Coulomb stress changes is interpreted as an unloading of a fault, thus inhibiting earthquake rupture. Although earthquakes indisputably result in an overall decrease in the net stress accumulated in a region, the patterns of stress change are such that certain regions surrounding a given earthquake experience an increase in stress. Most notably there is a marked Coulomb stress changes increase in the zone surrounding the rupture plane (the zone most likely to experience aftershocks) and two or more off-fault lobes where delayed triggering of subsequent mainshocks may occur [7]

\section{3/01/21 and 2013/07/02 Aceh Earthquakes}

Earthquake with $\mathrm{Mw}>7$ has no record on the Aceh segment. The Aceh earthquakes of 21 January $2013(\mathrm{Mw}=6.1)$ 
and 2 July $2013(\mathrm{Mw}=6.1)$ were the recent strong earthquakes that occurred on Aceh segment. Figure 2 shows centroid epicenter for the both earthquakes. Table 1 shows others source parameters of the earthquakes. The source parameters were used to compute Coulomb stress changes.

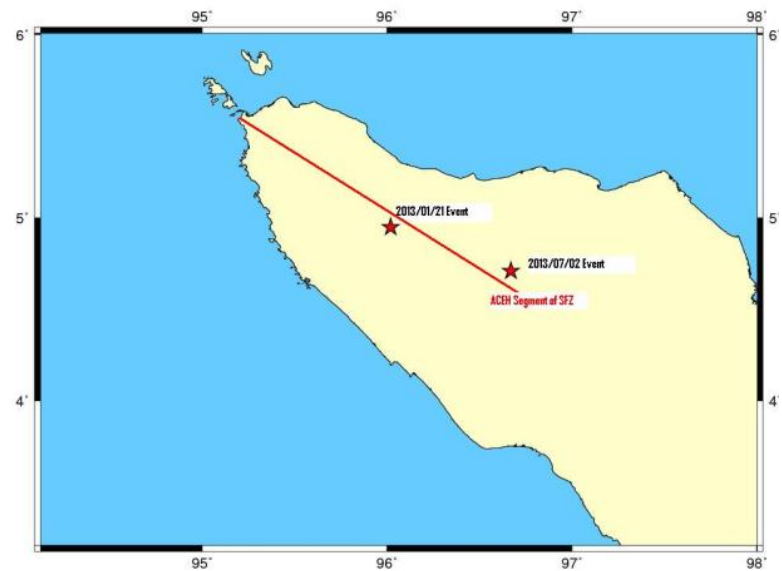

Figure 2. Epicenter of 2013/01/21 and 2013/07/02 events (red stars) from www.globalcmt.org and approximately of Aceh segment of SFZ (red line).

Table 1. CMT parameters of the 21 January and 2 July 2013 Aceh earthquake

\begin{tabular}{|c|c|c|c|c|c|c|c|c|}
\hline Event & Lat & Long & Depth & St1; St2 & Dp1; Dp2 & S11; S12 & Mw & $\begin{array}{c}\text { Number of } \\
\text { aftershocks } \\
\text { Mw }>5, \\
\text { depth }<20 \\
\mathrm{~km}\end{array}$ \\
\hline $2013 / 01 / 21$ & 4.95 & 96.02 & 17.1 & $37 ; 132$ & $73 ; 76$ & $-14 ;-162$ & 6.1 & 0 \\
\hline $2013 / 07 / 02$ & 4.71 & 96.67 & 12.0 & $34 ; 127$ & $77 ; 78$ & $-12 ;-166$ & 6.1 & 2 \\
\hline
\end{tabular}

(http://www.globalcmt.org/). St1 : strike 1, Dp1 : dip 1. Sli : slip 1

Table 2. Epicenters aftershocks of the 2 July 2013 Aceh earthquake

\begin{tabular}{|c|c|c|c|c|}
\hline Event & Lat & Long & Depth & Mw \\
\hline $2013 / 07 / 02 \quad 15: 36: 45$ & 4.59 & 96.73 & 10.0 & 5.2 \\
\hline $2013 / 07 / 02 \quad 13: 55: 40$ & 4.61 & 96.75 & 10.0 & 5.5 \\
\hline
\end{tabular}

(http://geofon.gfz-potsdam.de/eqinfo/)

\section{RESULTS}

We commence by assessing the Coulomb stress changes due to past $\mathrm{Mw}>$ 6 earthquakes in Aceh, Sumatra, Indonesia. We computed the Coulomb stress changes along the Aceh segment of SFZ at a centroid depth of $17.1 \mathrm{~km}$ for 2013/01/21 event and $12.0 \mathrm{~km}$ for 2013/07/02 event. The results are shown in Figure 3, increasing Coulomb stress changes of 2013/01/21 earthquake overlain with the epicenter of 2013/01/21 earthquake.

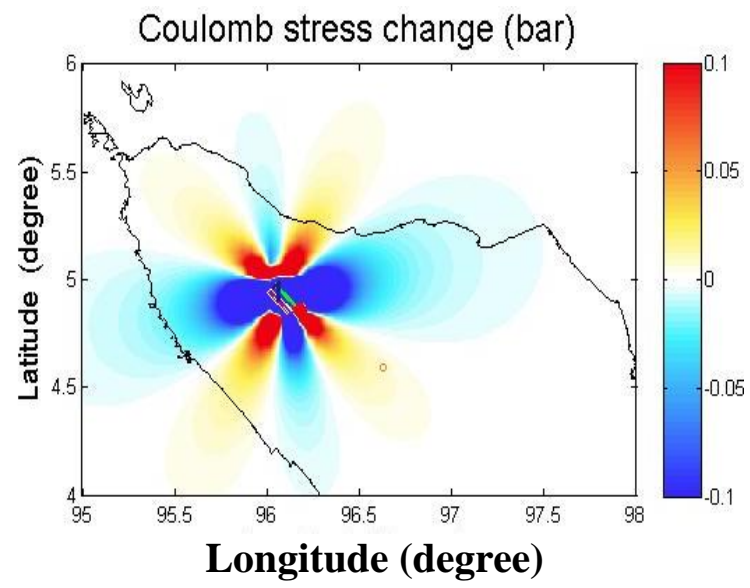

Figure 3. Coulomb stress changes for 2013/01/21 earthquake at centroid depth

$17.10 \mathrm{~km}$. Epicenter of 2013/07/02 eathquake (red circle) lie on increasing Coulomb stress changes. 


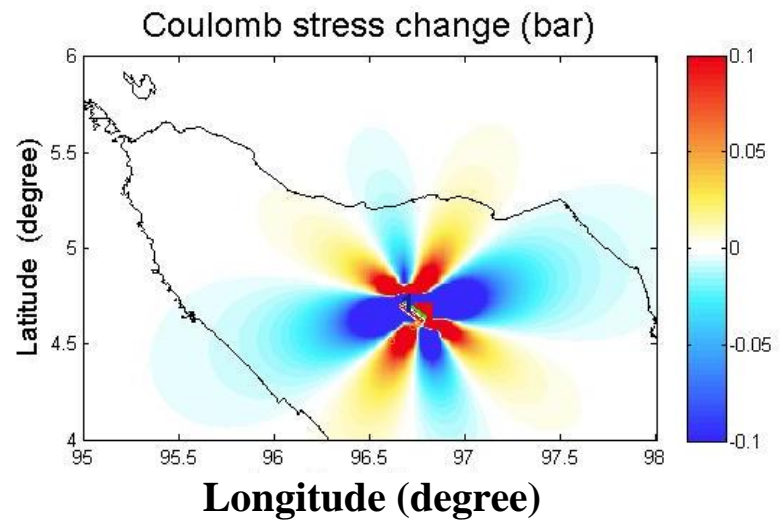

Figure 4. Coulomb stress changes for 2013/07/02 earthquake at centroid depth $12.00 \mathrm{~km}$. Epicenter of the two aftershocks (red circle) lie on largest Coulomb stress changes.

Figure 4, increasing Coulomb stress changes of 2013/07/02 earthquake overlain with the epicenters of the two ahtershocks in the Aceh segment seismic catalogue. Epicenters of the two epicenters revised manually by GEOFON catalogue (Table 2 ). It is evident that these two strong earthquakes are sufficiently close to form a "stress bridge" across the Aceh segment.

The three recorded earthquakes lie within or near regions of increasing Coulomb stress changes. A much closer inspection of the local geology and focal mechanisms (where available) is required to accurately model the stress changes due to past earthquakes. The results in Figure 3 and Figure 4 simply demonstrate that stress changes of up to 0.01 bar are expected at sufficiently large distance from the rupture planes of past earthquakes that the timing of nearby earthquakes may be altered by static stress interactions.

\section{CONCLUSIONS}

The increasing Coulomb stress changes will promote the occurrence of shallow focus aftershocks outside of the Aceh segment. Since shallow aftershocks are expected to have a higher damage potential, this is a valuable constraint for postmainshock mitigation efforts. While the Coulomb stress increase for a $\mathrm{Mw}=6.1$ earthquake may result in between 0.01 and
0.1 bar Coulomb stress increases. Increasing of this magnitude is comparable with that shown to result in Coulomb stress changes triggering in other seismogenic regions and hence must be considered in seismic hazard assessment, particularly the estimation of recurrence times or probabilities. Although preliminary in nature, these results highlight the need to consider Coulomb stress changes interactions when estimating the seismic hazard in Aceh region. Past earthquakes have occurred within sufficient proximity of mainshocks for Coulomb stress changes interactions to affect their timing..

\section{ACKNOWLEDGMENTS}

I gratefully acknowledges the contributions of the GEOFON-BMKG-IA network (http://webdc.eu) provided access to waveforms used in this research; I thank all the people who install, operate and maintain the seismic stations in Indonesia. The Global CMT Catalog (http://www.globalcmt.org/

MTsearch.html) provided access to CMT data used in this research. Furthermore, I thank Shinjii Toda, Ross Stein, Jian Lin, and Volkan Sivelgen who provided Coulomb 33 software to estimate Coulomb stress changes (http://earthquake.usgs.gov/research/modeli ng/coulomb/).

\section{REFERENCES}

[1] King, G.C.P., Stein, R.S., and Lin, J. 1994. Static Stress changes and the triggering of earthquakes, Bull. Seismol. Soc. Am., 84, pp. 935-953.

[2] Das, S. and Scholz, C. H. 1991. Offfault aftershock clusters caused by shear-stress increase. Bull. Seismol. Soc. Am., 71, 1669-1675.

[3] Harris, R. 1998. Introduction to special section: Stress triggers, stress shadows, and implication for seismic hazard, J. Geophys. Res., 103, 2434724358. 
[4] King, G. C. P. and Cocco, M.. 2000. Fault interaction by elastic stress changes: New clues from earthquake sequences. Adv. Geophys., 44, 1-38.

[5] Nalbant, S. S., Hubert, A. and King, G. C. P. 1998. Stress coupling between earthquakes in northwest Turkey and the north Aegean Sea. J. Geophys. Res., 1998, 103, 24,469-24,486.

[6] Shikha Rajput, V. K., Gahalaut and Vipul K., Sahu. 2005. Coulomb stress changes and aftershocks of recent Indian earthquakes. CURRENT SCIENCE, VOL. 88, NO. 4.

[7] Weatherley, D. 2006. Coulomb stress changes due to Queensland earthquakes and the implications for seismic risk assessment. Earthquake Engineering in Australia, Canberra 2426 November 2006.

[8] Parsons, T., Toda, S., Stein, R.S., Barka, A. and Dieterich, J.H. 2000. Heightened odds of large earthquakes near Istanbul: An interaction-based probability calculation, Science, 288, pp. 661-665.

[9] Natawidjaya D.H. 2007. The Sumatran Fault Zone - from Source to Hazard, Journal of Earthquake and Tsunami, 1, 21-47

[10]Madlazim, Santosa, Bagus Jaya, M. Lees, Jonathan and U., Widya. 2010. Earthquake Source Parameters at Sumatran Fault Zone: Identification of the Activated Fault Plane, Cent. Eur. J. Geosci.,2(4),2010.DOI:10.2478/v1008 5-010-0016-5.

[11]Okada, Y. 1992. Internal deformation due to shear and tensile faults in a half-space, Bull. Seismol. Soc. Am., 82, pp. 1018-1040.

[12]Toda, S. and Stein, R. S. 2000. Did stress triggering cause the large offfault aftershocks of the 25 March $1998 \mathrm{Mw}=8.1$ Antarctic plate earthquake?, Geophys. Res. Lett., 27, 2301-2304. 